\title{
Creative scientific dispute - different points of view on the protocol and execution of the ISAR-REACT 5 trial
}

\author{
Corresponding author: \\ Jacek Kubica, Collegium Medicum, \\ Nicolaus Copernicus University, \\ Torun, Poland, \\ e-mail: jwkubica@gmail.com
}

Medical Research Journal 2020;

Volume 5, Number 1, 41-45

10.5603/MRJ.a2020.0008

Copyright (C) 2020 Via Medica

ISSN 2451-2591

\begin{abstract}
Discordant interpretations of the results of clinical trials often drive scientific disputes.

Our position concerning the protocol and performance of the ISAR-REACT 5 trial have been termed as false and groundless in the recently published article. We deeply disagree with this judgement and still maintain all our opinions expressed in the previous publications, without any exceptions. As demonstrated in multiple studies, prasugrel has excellent effectiveness and predictability. In our previous publications, it was not the drug itself that we put under criticism, but rather the quality of the trial assessing the drug. As a consequence of this critical approach, we stated that taking into account the serious limitations of the ISAR-REACT 5 trial, its results should be taken with cautiousness.
\end{abstract}

To summarize, we remain open to further creative scientific dispute enriching both readers and authors. Key words: Prasugrel, ticagrelor, antiaggregation drugs, acute coronary syndrome, clinical trials

Med Res J 2020; 5 (1): 41-45

\section{Introduction}

Creative scientific dispute presenting results of clinical trials from different points of view is a valuable tool for enriching the knowledge of the adversaries and the readers.

One of the articles published in the latest issue of „Folia Cardiologica”, titled „Modern therapy of acute coronary syndromes based on prasugrel - available to Polish patients" [1], undermines the arguments adduced in our two earlier publications critical of the methodology of the ISAR-REACT 5 trial $[2,3]$. As authors of the former two publications, we feel obliged to refer to these objections.

We are deeply convinced that criticism can be of a stimulative value only when not left unresponded.

\section{Critical analysis and dispute}

The majority of our remarks concerning the protocol of the ISAR-REACT 5 trial [4] and its performance [5] were termed by our opponent as false and groundless. We deeply disagree with this judgement and still maintain all our opinions expressed in the previous publications [2, 3], without any exceptions.
The long-anticipated results of the ISAR-REACT 5 trial comparing ticagrelor with prasugrel turned out to be a surprise, pointing to superiority of prasugrel over ticagrelor and contradicting the trial's initial assumptions $[4,5]$. In our opinion this contradiction whatsoever does not enhance the validity of the results of the trial.

Our dispute adversary, truthfully notices our criticism of the open character of the trial, underestimation of non-compliance to recommended therapy and the form of follow-up based on telephone calls. Further, she states that these features in fact underlie the strength of the trial, rendering it closer to everyday clinical reality rather than concentrating on a highly selected population of a clinical trial [1]. We disagree with this opinion - none of the mentioned factors (open character of the trial, compliance underestimation, indirect contact with the patient) are relevant regarding the trial's inclusion and exclusion criteria and as such, they remain irrelevant with respect to patient selection. In our opinion, the situation is exactly opposite. The assumption of nearly absolute compliance (according to the authors of the ISAR-REACT 5 trial amounting $99.1 \%$ and $99.6 \%$ in the prasugrel and ticagrelor arm, respectively) seems quite risky and in fact it moves the results away from reality, rather than renders them closer to it $[2,3]$. 
Our opponent's [1] astonishment derived from our remarks concerning the ITT-type of analysis (intention-to-treat - population receiving the originally assigned treatment) and inclusion of patients who eventually did not receive the medication as originally allocated, is quite incomprehensible as we clearly stated an opposite fact, namely, that such method is commonly accepted in this type of clinical trials. However, in this specific case, taking into account the exceptionally high rate of study drug discontinuation (ticagrelor arm: 653 of 2012 patients (32\%), prasugrel arm: 609 of 2006 patients (30.4\%)), a significant bias might have occurred [5]. Therefore, it is not the methodology that we subject to criticism, but only the possible consequences of including into the analysis a surprisingly high number of patients who in fact were not treated with the originally assigned drug [2, 3]. Of note, among the 4018 patients randomized for the trial, the study drugs were discontinued in $820(20.4 \%)$ of them within first few days after randomization, even before discharge from hospital [5].

According to our opponent, it is quite unlikely that the difference in the rate of the primary endpoint (death, myocardial infarction or stroke) within a year following randomization between the ticagrelor $(9.8 \%)$ and prasugrel (6.8\%) arm is insignificant [1]. In order to clarify, we would like to clearly state that in our both publications a detailed statistical analysis of the primary endpoint in the ISAR-REACT 5 trial was presented [2, 3]. However, we also included information, which due to space constraints was published in the supplemental contents outside the main text, telling that the on-treatment analysis did not show significant differences between the study arms regarding the primary endpoint occurrence between discharge from hospital and either therapy discontinuation or follow-up completion [5]. We also highlighted that taking into account the fact that 1262 patients of those included in the analysis had had the study drug discontinued, while 37 patients were lost to follow-up, the absolute difference between both study groups in the primary endpoint occurrence amounted barely 47 cases and can hardly be considered significant $[2,3]$.

Our adversary also disagrees with our objections concerning the ISAR-STAR 5 trial, resulting from the comparison of its results with the outcomes reported for the TRITON-TIMI38 trial. She also finds our position stating that the differences in the primary endpoint rates between these both trials $(6.9 \%$ for ISAR-REACT 5 versus $9.9 \%$ for TRITON-TIMI 38) seem unexpected and hard to explain, to be surprising [1]. In response to these remarks - stating that such differences in outcomes between the both trials exist is simply acknowledging a fact rather than raising an objection against the ISAR-REACT 5 trial $[5,6]$. Regarding the other remark, we admit that we were and still are startled with this difference, and we seem to be not the only ones, as the outcomes of the ISAR-STAR 5 trial were an unexpected finding even for the authors of the trial [5]. We admit, we cannot explain the magnitude of the difference and we remain open for any explanatory suggestions for this fact. Interestingly, the major difference in the occurrence of the primary endpoint between the prasugrel arms of the ISAR-REACT 5 and TRITON-TIMI38 trials was not accompanied by analogous difference between the ticagrelor arms of these trials [5].

The Orville Wright quote: "If we all worked on the assumption that what is accepted as true is really true, there would be little hope of advance." used by our opponent as a comment, although otherwise arousing appreciation, in our opinion, in this specific setting is misguided and wrongful. We are deeply convinced that none of our two criticized papers [2, 3], neither our previous publications regarding antiaggregation therapy [7-74], legitimate assumptions that our intention is inhibition of progress through creation of opinion stagnation, instead of quest for the truth aimed at advance.

The closing critical remark addressed at our publications argues against our objections regarding the lack of identification of causes for patient exclusion from the safety analysis, pointing that such causes were reported in the original publication of the ISAR-REACT 5 trial [1]. Unfortunately, we cannot support this point of view, as the original report reveals that in 172 and 184 patients respectively randomized to ticagrelor and prasugrel, the initial diagnosis of acute coronary syndrome was not confirmed. According to the trial protocol, the consequence of this fact in case of prasugrel should be desisting from drug administration, in conjunction with exclusion of these patients from the safety analysis (modified intention to treat). The numbers reported in the original publication were 23 and 233 respectively and they do not correspond to the numbers of patients with unconfirmed diagnosis of acute coronary syndrome, while no explanation for the real numbers of exclusions in both groups were presented [5].

Following the critical review of our position, our opponent highlights the excellent results of acute coronary syndrome treatment based on prasugrel, in an attempt to convince the readers about the advantages of this P2Y12 receptor inhibitor [1]. In this aspect, we fully support her point of view, however in the global context of the paper, the initial reference to ticagrelor in the summary paragraph may surprise. The author indicates that ticagrelor is likely to produce intermittent dyspnea, occasionally leading to drug discontinuation [1], however she omits the crucial fact that ticagrelor is the only antiplatelet agent with proven reduction in cardiovascular mortality and all-cause mortality [75].

Juxtaposition of the final portion of the paper with its earlier part, critical of our publications, brings to 
mind an attempt of defending prasugrel. In this aspect, this action resembles convincing ones who are already convinced as prasugrel needs no defense. The effectiveness and predictability of prasugrel has been demonstrated in numerous publications, also those coming from our research team $[11,17,25,26,35,38$, $39,46,60,62,69]$, and undeniably prasugrel holds a strong position in multiple guidelines.

We would like to clearly stress that the critical remarks presented in our publications strictly apply to the quality of the drug-assessing study, not the drug itself. That is why we concluded that concerning the serious shortcomings of the ISAR-REACT 5 trial, its results should be taken with cautiousness [2, 3].

Concluding, we remain open to further creative scientific dispute enriching both readers and authors.

\section{References}

1. Wożakowska-Kapłon B. Nowoczesna terapia ostrych zespołów wieńcowych oparta na prasugrelu — dostępna dla polskiego pacjenta. Folia Cardiol. 2020; 15(1): 49-55, doi: 10.5603/fc.2020.0007.

2. Ostrowska M, Adamski P, Kubica J. ISAR-REACT 5: should this trial change clinical practice? Folia Cardiol. 2019; 14(5): 483-487, doi: 10.5603/FC.a2019.0099.

3. Kubica J, Jaguszewski M. ISAR-REACT 5 - What have we learned? Cardiol J. 2019; 26(5): 427-428, doi: 10.5603/CJ.a2019.0090, indexed in Pubmed: 31536136.

4. Schulz S, Angiolillo DJ, Antoniucci D, et al. Intracoronary Stenting and Antithrombotic Regimen: Rapid Early Action for Coronary Treatment (ISAR-REACT) 5 Trial Investigators. Randomized comparison of ticagrelor versus prasugrel in patients with acute coronary syndrome and planned invasive strategy--design and rationale of the iNtracoronary Stenting and Antithrombotic Regimen: Rapid Early Action for Coronary Treatment (ISAR-REACT) 5 trial. J Cardiovasc Transl Res. 2014; 7(1): 91-100, doi: 10.1007/s12265-013-9527-3, indexed in Pubmed: 24371012

5. Schüpke S, Neumann FJ, Menichelli M, et al. ISAR-REACT 5 Trial Investigators. Ticagrelor or Prasugrel in Patients with Acute Coronary Syndromes. N Engl J Med. 2019; 381(16): 1524-1534, doi: 10.1056/NEJMoa1908973, indexed in Pubmed: 31475799

6. Wiviott SD, Braunwald E, McCabe CH, et al. TRITON-TIMI 38 Investigators. Intensive oral antiplatelet therapy for reduction of ischaemic events including stent thrombosis in patients with acute coronary syndromes treated with percutaneous coronary intervention and stenting in the TRITON-TIMI 38 trial: a subanalysis of a randomised trial. Lancet. 2008; 371 (9621): 1353-1363, doi: 10.1016/S0140-6736(08)60422-5, indexed in Pubmed: 18377975.

7. Koziński M, Bielis L, Wiśniewska-Szmyt J, et al. Increased morning ADP-dependent platelet aggregation persists despite dual antiplatelet therapy in patients with first ST-segment elevation myocardial infarction: Preliminary report. Cardiol J. 2008; 15(6): 530-536, indexed in Pubmed: 19039757.

8. Kasprzak M, Koziński M, Bielis L, et al. Pantoprazole may enhance antiplatelet effect of enteric-coated aspirin in patients with acute coronary syndrome. Cardiol J. 2009; 16(6): 535-544, indexed in Pubmed: 19950090.

9. Witkowski A, Maciejewski P, Wasek W, et al. STEMI 2003 Registry Collaborators. Influence of different antiplatelet treatment regimens for primary percutaneous coronary intervention on all-cause mortality. Eur Heart J. 2009; 30(14): 1736-1743, doi: 10.1093/eurheartj/ehp114 indexed in Pubmed: 19376786.

10. Siller-Matula JM, Huber K, Christ G, et al. Impact of clopidogrel loading dose on clinical outcome in patients undergoing percutaneous coronary intervention: a systematic review and meta-analysis. Heart. 2011; 97(2): 98-105, doi: 10.1136/hrt.2010.195438, indexed in Pubmed: 20736210.

11. Navarese EP, Verdoia M, Schaffer A, et al. Ischaemic and bleeding complications with new, compared to standard, ADP-antagonist regimens in acute coronary syndromes: a meta-analysis of random- ized trials. QJM. 2011; 104(7): 561-569, doi: 10.1093/qimed/hcr069, indexed in Pubmed: 21572108

12. Kozinski M, Bielis L, Wisniewska-Szmyt J, et al. Diurnal variation in platelet inhibition by clopidogrel. Platelets. 2011; 22(8): 579-587, doi: 10.3109/09537104.2011.582900, indexed in Pubmed: 21627410.

13. Kubica A, Kozinski M, Navarese EP, et al. Intracoronary versus intravenous abciximab administration in STEMI patients: overview of current status and open questions. Curr Med Res Opin. 2011; 27(11): 2133-2144, doi: 10.1185/03007995.2011.621417, indexed in Pubmed: 21942506 .

14. Navarese EP, Kozinski M, Obonska K, et al. Clinical efficacy and safety of intracoronary vs. intravenous abciximab administration in STEMI patients undergoing primary percutaneous coronary intervention: a meta-analysis of randomized trials. Platelets. 2012; 23(4): 274-281, doi: 10.3109/09537104.2011.619602, indexed in Pubmed: 21988317.

15. Siller-Matula JM, Delle-Karth G, Lang IM, et al. Phenotyping vs. genotyping for prediction of clopidogrel efficacy and safety: the PEGASUS-PCI study. J Thromb Haemost. 2012; 10(4): 529-542, doi: 10.1111/j.1538-7836.2012.04639.x, indexed in Pubmed: 22260716.

16. Kubica J, Adamski P, Ostrowska M, et al. Ticagrelor, but not clopidogrel and prasugrel, prevents ADP-induced vascular smooth muscle cell contraction: a placebo-controlled study in rats. Thromb Res. 2012; 130(1): 65-69, doi: 10.1016/j.thromres.2011.12.029, indexed in Pubmed: 22265722.

17. Koziński M, Grześk G, Kubica J. [Optimal antiplatelet and antithrombotic therapy in patients with ST elevation myocardial infarction]. Kardiol Pol. 2012; 70(2): 206-212, indexed in Pubmed: 22427098.

18. Kubica J, Koziński M, Navarese EP, et al. Updated evidence on intracoronary abciximab in ST-elevation myocardial infarction: a systematic review and meta-analysis of randomized clinical trials. Cardiol J. 2012; 19(3): 230-242, doi: 10.5603/cj.2012.0044, indexed in Pubmed: 22641541

19. Koziński M, Kubica J. [High platelet reactivity during reperfusion - a new risk factor of no reflow?]. Kardiol Pol. 2012; 70(7): 685, indexed in Pubmed: 22825941.

20. Navarese EP, Buffon A, Kozinski M, et al. A critical overview on ticagrelor in acute coronary syndromes. QJM. 2013; 106(2): 105-115, doi: 10.1093/ajmed/hcs187, indexed in Pubmed: 23097390.

21. Tantry US, Jeong YH, Navarese EP, et al. Influence of genetic polymorphisms on platelet function, response to antiplatelet drugs and clinical outcomes in patients with coronary artery disease. Expert Rev Cardiovasc Ther. 2013; 11(4): 447-462, doi: 10.1586/erc.13.20, indexed in Pubmed: 23570358.

22. Grześk G, Kozinski M, Tantry US, et al. High-dose, but not low-dose, aspirin impairs anticontractile effect of ticagrelor following ADP stimulation in rat tail artery smooth muscle cells. Biomed Res Int. 2013; 2013 928271, doi: 10.1155/2013/928271, indexed in Pubmed: 23841099.

23. Kubica J, Kozinski M, Navarese EP, et al. Cangrelor: an emerging therapeutic option for patients with coronary artery disease. Curr Med Res Opin. 2014; 30(5): 813-828, doi: 10.1185/03007995.2014.880050, indexed in Pubmed: 24393016.

24. Ostrowska M, Adamski P, Koziński M, et al. Off-target effects of glycoprotein Ilb/llla receptor inhibitors. Cardiol J. 2014; 21(5): 458-464, doi: 10.5603/CJ.a2014.0020, indexed in Pubmed: 24526503.

25. Koziński M, Obońska K, Stankowska K, et al. Prasugrel overcomes high on-clopidogrel platelet reactivity in the acute phase of acute coronary syndrome and maintains its antiplatelet potency at 30-day follow-up. Cardiol J. 2014; 21 (5): 547-556, doi: 10.5603/CJ.a2014.0026, indexed in Pubmed: 24671900.

26. Adamski P, Koziński M, Ostrowska M, et al. Overview of pleiotropic effects of platelet P2Y12 receptor inhibitors. Thromb Haemost. 2014; 112(2): 224-242, doi: 10.1160/TH13-11-0915, indexed in Pubmed: 24763899 .

27. Siller-Matula JM, Lang IM, Neunteufl T, et al. Interplay between genetic and clinical variables affecting platelet reactivity and cardiac adverse events in patients undergoing percutaneous coronary intervention. PLoS One. 2014; 9(7): e102701, doi: 10.1371/journal.pone.0102701, indexed in Pubmed: 25051347.

28. Kubica A, Kasprzak M, Siller-Matula J, et al. Time-related changes in determinants of antiplatelet effect of clopidogrel in patients after myocardial infarction. Eur J Pharmacol. 2014; 742: 47-54, doi: 10.1016/j. ejphar.2014.08.009, indexed in Pubmed: 25199965.

29. Kubica J, Adamski P, Ostrowska M, et al. Influence of Morphine on Pharmacokinetics and Pharmacodynamics of Ticagrelor in Patients with Acute Myocardial Infarction (IMPRESSION): study protocol for a randomized controlled trial. Trials. 2015; 16: 198, doi: 10.1186/s13063015-0724-z, indexed in Pubmed: 25925591.

30. Kubica A, Kasprzak M, Obońska K, et al. Discrepancies in assessment of adherence to antiplatelet treatment after myocardial infarction. 
Pharmacology. 2015; 95(1-2): 50-58, doi: 10.1159/000371392, indexed in Pubmed: 25592409.

31. Kubica A, Obońska K, Kasprzak M, et al. Prediction of high risk of non-adherence to antiplatelet treatment. Kardiol Pol. 2016; 74(1) 61-67, doi: 10.5603/KP.a2015.0117, indexed in Pubmed: 26101025

32. Stolarek W, Kasprzak M, Obońska K, et al. Acetylsalicylic acid resistance risk factors in patients with myocardial infarction. Pharmacol Rep. 2015; 67(5): 952-958, doi: 10.1016/i.pharep.2015.02.006, indexed in Pubmed: 26398390.

33. Hobl EL, Reiter B, Schoergenhofer C, et al. Morphine decreases ticagrelor concentrations but not its antiplatelet effects: a randomized trial in healthy volunteers. Eur J Clin Invest. 2016; 46(1): 7-14, doi: 10.1111/eci.12550, indexed in Pubmed: 26449338.

34. Kubica J, Adamski P Ostrowska M et al. Morphine delays and attenuates ticagrelor exposure and action in patients with myocardial infarction: the randomized, double-blind, placebo-controlled IMPRESSION trial. Eur Heart J. 2016; 37(3): 245-252, doi: 10.1093/eurheartj/ehv547, indexed in Pubmed: 26491112

35. Winter MP, Koziński M, Kubica J, et al. Personalized antiplatelet therapy with P2Y12 receptor inhibitors: benefits and pitfalls. Postepy Kardio Interwencyjnej. 2015; 11(4): 259-280, doi: 10.5114/pwki.2015.55596, indexed in Pubmed: 26677375.

36. Kubica A, Obońska K, Fabiszak T, et al. Adherence to antiplatelet treatment with $\mathrm{P} 2 Y 12$ receptor inhibitors. Is there anything we can do to improve it? A systematic review of randomized trials. Curr Med Res Opin. 2016; 32(8): 1441-1451, doi: 10.1080/03007995.2016.1182901, indexed in Pubmed: 27112628.

37. Kubica J, Kubica A, Jilma B, et al. Impact of morphine on antiplatelet effects of oral P2Y12 receptor inhibitors. Int J Cardiol. 2016; 215: 201 208, doi: 10.1016/i.ijcard.2016.04.077, indexed in Pubmed: 27128531.

38. Gurbel PA, Myat A, Kubica J, et al. State of the art: Oral antiplatelet therapy. JRSM Cardiovasc Dis. 2016; 5: 2048004016652514 , doi 10.1177/2048004016652514, indexed in Pubmed: 27298725

39. Siller-Matula JM, Specht S, Kubica J, et al. Abciximab as a bridging strategy to overcome morphine-prasugrel interaction in STEM patients. Br J Clin Pharmacol. 2016; 82(5): 1343-1350, doi: 10.1111/bcp.13053, indexed in Pubmed: 27366874.

40. Koziński M, Ostrowska M, Adamski $P$, et al. Which platelet function test best reflects the in vivo plasma concentrations of ticagrelor and its active metabolite? The HARMONIC study. Thromb Haemost. 2016; 116(6): 1140-1149, doi: 10.1160/TH16-07-0535, indexed in Pubmed $\underline{27628615}$

41. Adamski P, Adamska U, Ostrowska M, et al. New directions for pharmacotherapy in the treatment of acute coronary syndrome. Expert Opin Pharmacother. 2016; 17(17): 2291-2306, doi 10.1080/14656566.2016.1241234, indexed in Pubmed: 27677394.

42. Myat A, Tantry US, Kubica J, et al. Current controversies in the use of aspirin and ticagrelor for the treatment of thrombotic events. Expert Rev Cardiovasc Ther. 2016; 14(12): 1361-1370, doi 10.1080/14779072.2016.1247693, indexed in Pubmed: 27740874.

43. Niezgoda P, Sikora J, Barańska M, et al. Crushed sublingual versus oral ticagrelor administration strategies in patients with unstable angina. A pharmacokinetic/pharmacodynamic study. Thromb Haemost. 2017; 117(4): 718-726, doi: 10.1160/TH16-08-0670, indexed in Pubmed: 28203684.

44. Kubica J, Adamski $P$, Paciorek $P$, et al. Anti-aggregation therapy in patients with acute coronary syndrome - recommendations for medical emergency teams. Experts' standpoint. Kardiol Pol. 2017; 75(4) 399-408, doi: 10.5603/KP.a2017.0057, indexed in Pubmed: 28421594

45. Adamski P, Ostrowska M, Sikora J, et al. Comparison of Ticagrelor Pharmacokinetics and Pharmacodynamics in STEMI and NSTEM Patients (PINPOINT): protocol for a prospective, observational, single-centre study. BMJ Open. 2017; 7(4): e013218, doi: 10.1136/bmjopen-2016-013218, indexed in Pubmed: 28446521.

46. Schoergenhofer C, Hobl EL, Staudinger T, et al. Prasugrel in critically ill patients. Thromb Haemost. 2017; 117(8): 1582-1587, doi 10.1160/TH17-03-0154, indexed in Pubmed: 28692105.

47. Adamski P, Sikora J, Laskowska E, et al. Comparison of bioavailability and antiplatelet action of ticagrelor in patients with ST-elevation myocardial infarction and non-ST-elevation myocardial infarction: A prospective, observational, single-centre study. PLoS One. 2017 12(10): e0186013, doi: 10.1371/journal.pone.0186013, indexed in Pubmed: 29023473.

48. Wolff G, Navarese EP, Brockmeyer M, et al. Perioperative aspirin therapy in non-cardiac surgery: A systematic review and meta-analysis of randomized controlled trials. Int J Cardiol. 2018; 258: 59-67, doi: 10.1016/j.ijcard.2017.12.088, indexed in Pubmed: 29544957.

49. Kubica J, Adamski P, Buszko K, et al. Rationale and Design of the Effectiveness of LowEr maintenanCe dose of TicagRelor early After myocardial infarction (ELECTRA) pilot study. Eur Heart J Cardiovasc Pharmacother. 2018; 4(3): 152-157, doi: 10.1093/ehjcvp/pvx032, indexed in Pubmed: 29040445

50. Bartko J, Schoergenhofer C, Schwameis M, et al. Morphine Interaction with Aspirin: a Double-Blind, Crossover Trial in Healthy Volunteers. J Pharmacol Exp Ther. 2018; 365(2): 430-436, doi: 10.1124/jpet.117.247213, indexed in Pubmed: 29540563.

51. Kubica J, Adamski P Paciorek P et al. Treatment of patients with acute coronary syndrome: Recommendations for medical emergency teams: Focus on antiplatelet therapies. Updated experts' standpoint. Cardiol J. 2018; 25(3): 291-300, doi: 10.5603/CJ.a2018.0042, indexed in Pubmed: 29671864

52. Navarese EP, Wernly B, Lichtenauer M, et al. Dual vs single antiplatelet therapy in patients with lower extremity peripheral artery disease A meta-analysis. Int J Cardiol. 2018; 269: 292-297, doi: 10.1016/j. iicard.2018.07.009, indexed in Pubmed: 30045826

53. Adamski P, Buszko K, Sikora J, et al. Metabolism of ticagrelor in patients with acute coronary syndromes. Sci Rep. 2018; 8(1): 11746 , doi: 10.1038/s41598-018-29619-9, indexed in Pubmed: 30082687.

54. Tantry U, Chaudhary R, Kubica J, et al. Cangrelor for the treatment of patients with Arterial Thrombosis. Expert Opin Pharmacother. 2018; 19(12): 1389-1398, doi: 10.1080/14656566.2018.1506767, indexed in Pubmed: 30102083

55. Sikora J, Niezgoda P, Barańska M, et al. METoclopramide Administration as a Strategy to Overcome MORPHine-ticagrelOr Interaction in PatientS with Unstable Angina PectorlS-The METAMORPHOSIS Trial. Thromb Haemost. 2018; 118(12): 2126-2133, doi: 10.1055/s-00381675605 , indexed in Pubmed: $\underline{30453344}$.

56. Kubica J, Adamski P, Buszko K, et al. Platelet inhibition with standard vs. lower maintenance dose of ticagrelor early after myocardial infarction (ELECTRA): a randomized, open-label, active-controlled pharmacodynamic and pharmacokinetic study. Eur Heart J Cardiovasc Pharmacother. 2019; 5(3): 139-148, doi: 10.1093/ehjcvp/pvz004, indexed in Pubmed: 30689800.

57. Umińska JM, Ratajczak J, Buszko K, et al. Impact of mild therapeutic hypothermia on bioavailability of ticagrelor in patients with acute myocardial infarction after out-of-hospital cardiac arrest. Cardiol J. 2019 [Epub ahead of print], doi: 10.5603/CJ.a2019.0024, indexed in Pubmed: 30799546

58. Boinska J, Koziński M, Kasprzak M, et al. Diurnal variations in tissue factor and tissue factor pathway inhibitor concentrations in relation to on-treatment platelet reactivity: an analysis of patients with acute myocardial infarction. Platelets. 2019 [Epub ahead of print]: 1-7, doi: 10.1080/09537104.2019.1693037, indexed in Pubmed: 31744370.

59. Adamski P, Buszko K, Sikora J, et al. Determinants of high platelet reactivity in patients with acute coronary syndromes treated with ticagrelor. Sci Rep. 2019; 9(1): 3924, doi: 10.1038/s41598-019-40628-0, indexed in Pubmed: 30850677

60. Ostrowska M, Kubica J, Adamski P, et al. Stratified Approaches to Antiplatelet Therapies Based on Platelet Reactivity Testing. Front Cardiovasc Med. 2019; 6: 176, doi: 10.3389/fcvm.2019.00176, indexed in Pubmed: 31850373

61. Gue YX Spinthakis N Farag M et al Impact of Preadmission Morphine on Reinfarction in Patients With ST-Elevation Myocardial Infarction Treated With Percutaneous Coronary Intervention: A Meta-Analysis. Clin Pharmacol Ther. 2020 [Epub ahead of print], doi: 10.1002/cpt.1798, indexed in Pubmed: 31990051.

62. Adamski P, Adamska U, Ostrowska M, et al. Evaluating current and emerging antithrombotic therapy currently available for the treatment of acute coronary syndrome in geriatric populations. Expert Opin Pharmacother. 2018; 19(13): 1415-1425, doi: 10.1080/14656566.2018.1510487, indexed in Pubmed: 30132731.

63. Barańska M, Niezgoda P Kubica J. The influence of naloxone on pharmacokinetics and pharmacodynamics of ticagrelor in patients with unstable angina pectoris receiving concomitant treatment with morphine - a protocol of a randomized trial. Med Res J. 2018; 3(4): 227-231, doi: 10.5603/mri.a2018.0035.

64. Kołodziejczak M, Navarese E, Kubica J. Rationale and design of PREvalence of DyspneA in patients treated with TicagrelOR (PREDATOR) program. Med Res J. 2018; 3(4): 215-220, doi: 10.5603/mrj. a2018.0037.

65. Umińska J, Koziński M, Pstragowski K, et al. Platelet reactivity during mild therapeutic hypothermia in patients with acute myocardial infarction treated with ticagrelor: study protocol of a single-centre study. Med Res J. 2017; 1(4): 115-119, doi: 10.5603/mrj.2016.0021.

66. Niezgoda P, Sikora J, Barańska M, et al. Impact of ticagrelor administration strategy on its pharmacokinetics and pharmacodynamics in patients with unstable angina pectoris: a protocol of a randomized study. Med Res J. 2016; 1(1): 10-14, doi: 10.5603/mri.2016.0002. 
67. Kubica A, Kasprzak M, Obońska K, et al. Impact of health education on adherence to clopidogrel and clinical effectiveness of antiplatelet treatment in patients after myocardial infarction. Med Res J. 2016 3(4): 154-159, doi: 10.5603/fmc.2015.0010.

68. Adamski P, Ostrowska M, Sroka W, et al. Does morphine administration affect ticagrelor conversion to its active metabolite in patients with acute myocardial infarction? A sub-analysis of the randomized double-blind, placebo- -controlled IMPRESSION trial. Med Res J. 2015; 3(3): 100-106, doi: 10.5603/fmc.2015.0003.

69. Kasprzak M, Molska M, Obońska K, et al. Variability of prasugre antiplatelet effect in patients with acute coronary syndrome. Med Res J. 2015; 3(3): 117-124, doi: 10.5603/fmc.2015.0006.

70. Laskowska E, Ostrowska M, Koziński M, et al. The influence of genetic polymorphisms of CYP2C19 and ABCB1 on ADP-induced platele aggregation in clopidogrel-treated patients: A comparison between the index hospitalization for myocardial infarction and the 3-month follow-up visit. Folia Medica Copernicana. 2015; 3(2): 62-71.
71. Kubica J. The optimal antiplatelet treatment in an emergency setting Folia Medica Copernicana. 2014; 2(3): 73-76.

72. Kubica A, Obońska K, Kasprzak M, et al. The impact of metabolic syndrome on the antiplatelet effect of clopidogrel and aspirin in patients with acute coronary syndrome. Folia Medica Copernicana 2014; 2(2): 66-72

73. Kubica A, Kasprzak M, Obońska K, et al. Impact of CYP2C19 polymorphisms on antiplatelet efficacy of clopidogrel in patients after myocardial infarction. Folia Medica Copernicana. 2013; 1(1): 12-17.

74. Kasprzak M, Koziński M, Stankowska K, et al. Enhanced antiplatelet effect of enteric-coated acetylsalicylic acid in co-administration with pantoprazole. Folia Medica Copernicana. 2013; 1(1): 5-11.

75. Wallentin L, Becker RC, Budaj A, et al. PLATO Investigators. Ticagrelor versus clopidogrel in patients with acute coronary syndromes. N Engl J Med. 2009; 361(11): 1045-1057, doi: 10.1056/NEJMoa0904327, indexed in Pubmed: 19717846. 